\title{
Secular change in waist circumference and waist-height ratio and optimal cutoff of waist-height ratio for abdominal obesity among Korean children and adolescents over 10 years
}

\author{
Min Sub Kim, MD', Se Young Kim, MD', Jae Hyun Kim, MD² \\ ${ }^{1}$ Department of Pediatrics, Bundang Jesaeng General Hospital, Daejin Medical Center, Seongnam, ${ }^{2}$ Department of Pediatrics, Seoul National University Bundang \\ Hospital, Seongnam, Korea
}

Purpose: This study aimed to evaluate the time trends of waist circumference (WC) and waist-height ratio (WHR), and to present WC and WHR distributions with optimal WHR cutoff for abdominal obesity in Korean children and adolescents.

Methods: We performed a retrospective cross-sectional analysis of data from 13,257 children and adolescents (6,987 boys and 6,270 girls) aged 6-18 years who were included in the third to sixth Korea National Health and Nutrition Examination Survey (KNHANES, 2005-2015). Linear regression analyses were used to identify secular changes in WC and WHR by age, sex, and KNHANES waves. A receiver operating characteristic curve analysis was used to determine the optimal WHR cutoff values for abdominal obesity and cardiometabolic risk factors.

Results: The mean WC and WHR distributions from 2005 to 2015 showed no significant secular changes between the KNHANES 4 waves ( $P$ for trend $\geq 0.05$ in all ages and both sexes). The mean WCs in the present study were lower than those in the 2007 Korean National Growth Charts. The mean WHR at ages $<13$ years was statistically higher in the boys than in the girls, but did not significantly differ between the sexes among those aged 13 to 18 years. The optimal WHR cutoff for abdominal obesity was 0.48 (area under the curve, $0.985 ;$ 95\% confidence interval, $0.985-0.985$ ) in the 13 - to 18-yearold adolescents.

Conclusion: WC and WHR showed no secular changes over 10 years. The optimal WHR cutoff for abdominal obesity of 0.48 is useful for diagnosing and managing obesity and thus preventing obesityrelated cardiometabolic complications in 13- to 18-year-old Korean adolescents.

Key words: Abdominal obesity, Child, Adolescent

\section{Introduction}

An increase in childhood obesity and related complications have been one of the greatest causes for concern worldwide for the past 30 years. ${ }^{1,2)}$ Insulin resistance in obese children could play a pivotal role as a 'driving force' behind the association of metabolic syndrome with other conditions, such as dyslipidemia and hypertension. ${ }^{3,4)}$ Childhood obesity is an important cardiovascular risk factor and is associated with increased rates of premature death. Abdominal obesity has also been reported as a risk factor for cardiovascular and metabolic disease in younger children. ${ }^{6-8)}$ Thus, the issue of prevention and control of obesity in younger individuals is increasing in importance.

Body mass index (BMI) and waist circumference (WC) have been used as traditional
Corresponding author: Jae Hyun Kim, MD Department of Pediatrics, Seoul National University Bundang Hospital, Seongnam 13620, Korea Tel: +82-31-787-7287

Fax: +82-31-787-4054

E-mail: pedendo@snubh.org https://orcid.org/0000-0002-0203-7443

Received: 7 September, 2018

Revised: 26 November, 2018

Accepted: 3 December, 2018

Copyright @ 2019 by The Korean Pediatric Society

This is an open-access article distributed under the terms of the Creative Commons Attribution NonCommercial License (http://creativecommons.org/ licenses/by-nc/4.0/ which permits unrestricted noncommercial use, distribution, and reproduction in any medium, provided the original work is properly cited. 
diagnostic tools to measure obesity and central adiposity. Both BMI and WC are considered useful parameters to identify cardiometabolic risks. However, there are some limitations to these currently used measures of adiposity. BMI and WC are strongly linked with ethnicity, age, and sex in children and adolescents. Age- and sexspecific reference tables are required to assess an individuals' status of adiposity.") Although BMI is usually well related to body fat, BMI cannot fully reflect body composition and sometimes cannot distinguish fat tissues from muscle mass, because BMI contains information for height and weight only. ${ }^{10)} \mathrm{WC}$ is a commonly used index to diagnose abdominal obesity, defined as 90th percentile or more by age and sex. WC is height-dependent, which might lead overor underestimation of abdominal obesity according to the height of children. In recent years, the waist-height ratio (WHR), which divides the WC by height, is also being used as an alternative index for the assessment of abdominal obesity. WHR has the advantage of being both a simple and convenient measurement. It has been reported the WHR is more accurate than BMI and WC in identifying cardiometabolic risk in adults. ${ }^{11)}$ In a prior systematic review, studies from 14 different countries including Caucasian, Asian, and Central American subjects showed that a WHR of $\geq 0.50$ covers all cardiometabolic outcomes in both men and women. ${ }^{12)}$ In children and adolescents, there are reports that WHR is more suitable than WC and BMI for indicating the percent body fat in the United States ${ }^{13)}$ and some studies demonstrate that WHR and BMI produce similar results in identifying cardiometabolic risk worldwide. ${ }^{14-17)}$ Some studies using WHR have been reported in Korea. The results of these studies showed that WHR is a similar or better index for screening abdominal obesity with or without overweight or obesity, when compared with BMI. WHR is helpful in determining children at higher cardiometabolic risk. ${ }^{18-21)}$ Some of these studies presented the cutoff values obtained. ${ }^{19,22)}$

Although previous studies of WHR have been published, the distribution of WHR by sex and age in Korean children and adolescents has not been examined. In addition, there is a lack of analysis as to whether a WHR value of 0.5 is an appropriate cutoff of abdominal obesity and cardiometabolic risk in the pediatric population. Thus, the aims of this study were (1) to identify the secular changes of WC and WHR, (2) to compare WC with the prior Korean reference, (3) to confirm the distribution of mean WHR values by age and sex, and (4) to determine if WHR cutoff value of 0.5 is an appropriate predicting factor of cardiometabolic risk in childhood, using nationally representative data in children and adolescents.

\section{Materials and Methods}

\section{Study population}

Data from children and adolescents aged 6-18 years were used, which were obtained from the Korea National Health and Nutrition
Examination Survey (KNHANES) (2005-2015). The KNHANES, a nationwide survey, is performed annually to collect data cross-sectionally and to assess the health and nutritional status of the Korean population by using a multistage clustered probability sampling study design. In this study, the cross-sectional data was composed of 4 waves, consisting of the 3rd (2005), 4th (2007-2009), 5th (20102012), and 6th (2013-2015) wave.

Of the 107,498 participants (male, 49,693; female, 57,805) in KNHANES, 18,916 children and adolescents aged 6-18 years (boys, 9,920; girls, 8,996) were selected. Finally, 13,257 subjects (boys, 6,987 ; girls, 6,270) were included for the analysis after excluding children and adolescents without any record of height, weight, or WC $(n=5,659)$ (Supplementary Table 1). For the subgroup analysis, 5,267 participants aged 13-18 years (boys, 2,781; girls, 2,486) fasted for at least 8 hours prior to laboratory tests were included.

The Institutional Review Board of the Korea Centers for Disease Control and Prevention approved the KNHANES. All participants gave informed consent before data collection. The protocol of the present study was approved by the Institutional Review Board of Bundang Jesaeng General Hospital (approval number: PD18-02). All methods were performed according to the Declaration of Helsinki.

\section{Anthropometric measurements and laboratory tests}

All anthropometric measurements were conducted by trained individuals according to the prescribed protocol. Height measurement was used a stadiometer (Seca 225, Seca, Hamburg, Germany) and recorded to the nearest $0.1 \mathrm{~cm}$. Weight measurement was performed using an electronic balance (GL-6000-20, G-tech, Seoul, Korea) and recorded to the nearest $0.1 \mathrm{~kg}$. WC was measured with the end expiratory state of subjects at his/her midpoint between lower end of the last rib cage and the upper rim of the iliac crest using a tape measure (Seca 200, Seca) and recorded to nearest $0.1 \mathrm{~cm}$. WHR was calculated by dividing WC $(\mathrm{cm})$ by height $(\mathrm{cm})$. Blood pressure (BP) was measured with subjects resting in a sitting position over 5 minutes and using a mercury sphygmomanometer (Baumanometer Desk Model 3020, WA Baum, Co., Copiague, NY, USA).

Blood tests were performed after 8 hours or more fasting. Fasting plasma glucose (FPG), triglyceride and high-density lipoprotein (HDL) cholesterol levels were measured using a Hitachi Automatic Analyzer 7600 (Hitachi, Tokyo, Japan). Glycated hemoglobin ( $\mathrm{HbA}_{1 \mathrm{c}}$ ) was measured using high performance liquid chromatography (HLC-723G7; Tosoh, Tokyo, Japan), which is the method certified by the National Glycohemoglobin Standardization Program.

Abdominal obesity was defined as WC $\geq 90$ th percentile for age and sex using Korean reference data from the 2007 Korean National Growth Charts. ${ }^{23)}$ Elevated BP was defined as systolic or diastolic BP $\geq 90$ th percentile for age and sex using the 2007 reference. ${ }^{24)}$ Hyperglycemia was defined as $\mathrm{FPG} \geq 100 \mathrm{mg} / \mathrm{dL}$. Elevated $\mathrm{HbA}_{1 \mathrm{c}}$ was defined as $\mathrm{HbA}_{1 \mathrm{c}} \geq 5.7 \%$. High triglyceride was defined as triglyceride $\geq 150 \mathrm{mg} / \mathrm{dL}$. Low HDL cholesterol was defined as HDL cholesterol 
$<40 \mathrm{mg} / \mathrm{dL}$ for boys aged $10-18$ years, $<40 \mathrm{mg} / \mathrm{dL}$ for girls aged $10-$ 16 years and $<50 \mathrm{mg} / \mathrm{dL}$ for girls aged $\geq 16$ years.

\section{Statistical analysis}

All statistical analyses were performed using Stata 14.2 software (StataCorp LP, College Station, TX, USA) and GraphPad Prism version 7.04 for Windows (GraphPad Software, La Jolla, CA, USA). For the statistical analysis, an appropriated sample weight was applied to each participant assigned for the design of KNHANES. Continuous variables were expressed as weighted mean \pm standard error and categorical variables as weighted percentage.

Differences in WC and WHR by sex were compared using a Student $t$ test. Differences in WC and WHR by KNHANES waves were compared using linear regression analysis. Percentile values of WC and WHR were generated according to sex and age. Receiver operating characteristic (ROC) curve analysis was used to identify the optimal threshold of WHR in predicting the cardiometabolic risk factor including abdominal obesity, elevated BP, hyperglycemia, elevated $\mathrm{HbA}_{1 c}$, High triglyceride, and low HDL cholesterol. The areas under the ROC curves (AUC) were obtained for each parameter. The point at which the sum of sensitivity and specificity is maximized was defined as optimal cutoff. The sensitivity, specificity, positive predictive value, and negative predictive value at the optimal cutoff were obtained and compared with the values at WHR 0.5 to validate usefulness as universal predictive marker in children and adolescents. $P<0.05$ was considered to statistically significant.

\section{Results}

\section{Lack of secular changes of WC and WHR from the 3rd to 6th waves of KNHANES}

The WC and WHR trends of mean values according to age in boys and girls were similar between all 4 waves of KNHANES from 2005 to 2015. There were no statistically significant differences in mean WC, except in 17-year-old boys ( $P=0.032)$ and 9- and 14-year-old girls ( $P=0.046$ and $P=0.025$, respectively) (Supplementary Table 2 ). Mean WHR values for age do not have any significant difference between 4 waves, apart from mean WHR of 17 years old boys ( $P=$ 0.019) (Supplementary Table 3).

\section{Comparison of mean WC with 2007 Korean National Growth Charts}

Age- and sex-specific mean values of WC and WHR were obtained (Table 1). Mean WC increased with age in both boys and girls. Mean WC of boys in all ages was significantly higher than of girls and showed a clear difference between sexes $(P<0.001)$ (Table 1$)$. Compared with the 2007 Korean National Growth Charts, the mean WC and percentile for 10th, 50th, and 90th curves of boys enrolled in KNHANES tended to be lower for all ages (Fig. 1). In girls, the percentile curves from KNHANES appear to be lower than the 2007 reference, but the differences seem to be less than in boys. Based on data from the 3rd to 6th KNHANES, we were able to express WC percentile values, as shown in Table 2 for both boys and girls.

\section{Distribution of WHR values by sex and age}

Mean WHR falls within the range of 0.421-0.451 for each sex and age (Table 1). Mean male WHR was significantly greater than that of females aged 6 to 12 years $(P<0.001)$. In particular, the peak

Table 1. Waist circumference and waist-height ratio by sex and age

\begin{tabular}{|c|c|c|c|c|c|c|}
\hline \multirow{2}{*}{ Age (yr) } & \multicolumn{3}{|c|}{ Waist circumference (cm) } & \multicolumn{3}{|c|}{ Waist-height ratio } \\
\hline & Boys & Girls & $P$ value & Boys & Girls & $P$ value \\
\hline 6 & $54.3 \pm 0.4$ & $52.3 \pm 0.3$ & $<0.001$ & $0.451 \pm 0.002$ & $0.439 \pm 0.002$ & $<0.001$ \\
\hline 7 & $56.3 \pm 0.3$ & $54.0 \pm 0.3$ & $<0.001$ & $0.445 \pm 0.002$ & $0.431 \pm 0.002$ & $<0.001$ \\
\hline 8 & $59.6 \pm 0.4$ & $56.5 \pm 0.3$ & $<0.001$ & $0.451 \pm 0.003$ & $0.433 \pm 0.002$ & $<0.001$ \\
\hline 9 & $61.8 \pm 0.4$ & $59.6 \pm 0.4$ & $<0.001$ & $0.450 \pm 0.003$ & $0.436 \pm 0.003$ & $<0.001$ \\
\hline 10 & $65.1 \pm 0.5$ & $61.2 \pm 0.4$ & $<0.001$ & $0.456 \pm 0.003$ & $0.426 \pm 0.002$ & $<0.001$ \\
\hline 11 & $67.3 \pm 0.5$ & $63.8 \pm 0.4$ & $<0.001$ & $0.450 \pm 0.003$ & $0.425 \pm 0.002$ & $<0.001$ \\
\hline 12 & $68.8 \pm 0.5$ & $65.6 \pm 0.4$ & $<0.001$ & $0.439 \pm 0.003$ & $0.421 \pm 0.002$ & $<0.001$ \\
\hline 13 & $70.6 \pm 0.5$ & $67.4 \pm 0.4$ & $<0.001$ & $0.431 \pm 0.003$ & $0.426 \pm 0.002$ & 0.178 \\
\hline 14 & $72.6 \pm 0.5$ & $68.3 \pm 0.4$ & $<0.001$ & $0.430 \pm 0.003$ & $0.428 \pm 0.003$ & 0.515 \\
\hline 15 & $74.0 \pm 0.5$ & $68.5 \pm 0.5$ & $<0.001$ & $0.431 \pm 0.003$ & $0.426 \pm 0.002$ & 0.219 \\
\hline 16 & $74.5 \pm 0.5$ & $69.6 \pm 0.5$ & $<0.001$ & $0.430 \pm 0.003$ & $0.433 \pm 0.003$ & 0.485 \\
\hline 17 & $75.0 \pm 0.5$ & $70.1 \pm 0.5$ & $<0.001$ & $0.432 \pm 0.003$ & $0.435 \pm 0.003$ & 0.530 \\
\hline 18 & $76.8 \pm 0.6$ & $70.8 \pm 0.5$ & $<0.001$ & $0.441 \pm 0.003$ & $0.440 \pm 0.003$ & 0.753 \\
\hline
\end{tabular}

Values are presented as weighted mean \pm standard error. 

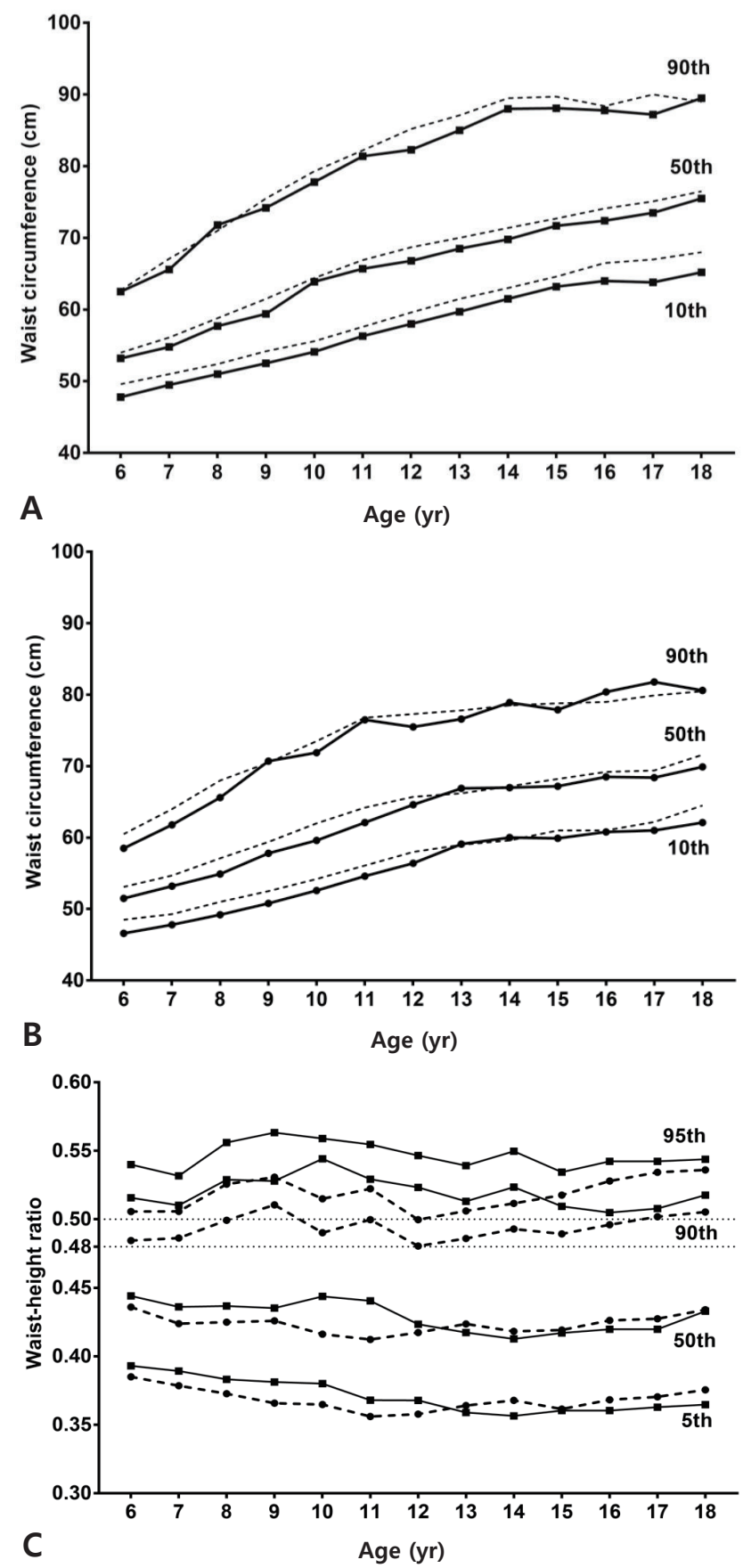

Fig. 1. Waist circumference percentile (10th, 50th, and 90th) for boys (A) and girls (B) and waist-to-height ratio percentiles (5th, 50th, 90th, and 95 th) by sex $(C)$. In $(A)$ and $(B)$, the dotted lines are the percentile lines from the Korean reference data (reference 23), and the closed lines are from the present study. In (C), the closed line denotes boys, and the dotted line denotes girls.

difference is most obvious in boys at the age of 10 years compared with girls (boy, $0.456 \pm 0.003$ vs. girls, $0.426 \pm 0.002 ; P<0.001$ ). Consequently, the mean WHR decreases steadily from 10 to 14 years in boys and decreases from 9 to 12 years in girls. However, there was no statistical difference between WHR of boys and girls from 13 to 18 years of age (Table 1, Fig. 1). The percentile values for the age in boys and girls are shown in Table 3.

\section{WHR cutoff values}

Table 4 present the results of the ROC curve analysis used to determine optimal WHR cutoff values between 13 to 18 years of age for cardiometabolic risk factors, including abdominal obesity, high fasting glucose, high $\mathrm{HbA}_{1 c}$, high triglyceride, low HDL cholesterol and elevated BP. The optimal WHR cutoff values capable of predicting all cardiometabolic risk factors were under 0.5 with higher sensitivity and negative predictive values as shown in Table 4. The optimal cutoff value for abdominal obesity was the highest as 0.480 with an AUC of 0.985 (sensitivity, 97.6\%; specificity, 91.3\%). The optimal WHR cutoff value for high triglyceride was 0.462 with an AUC of 0.735 (sensitivity, 59.0\%; specificity, 78.4\%). The other optimal WHR cutoff values for cardiometabolic risk factors ranged from 0.442 to 0.462 with AUC from 0.545 to 0.645 .

\section{Discussion}

This is the first study evaluating change over time in WC and WHR in Korean children and adolescents. Mean of WC and WHR in Korean children and adolescents have been maintained without significant change between 4 waves of KNHANES over 10 years, in contrast to the previously reported trend of increasing obesity and metabolic syndrome in Korea. ${ }^{25}$ Mean WC was lower than in the 2007 Korean National Growth Charts. Mean WHR was similar between boys and girls aged 13 years or more. Based on this, the obtained cutoff value to determine abdominal obesity was 0.48 , independent of sex, which was lower than 0.5.

As interest in WC and WHR has increased, a search for reference index measurement representing the populations of specific countries has been conducted worldwide. Fig. 2 compares the mean of previously published worldwide WHR data with the data generated in this study. According to a Norwegian study ${ }^{26)} 6$ - to 8-year-old girls have longer mean WC than the Korean girls presented in this paper and the mean WC of girls aged 9 years or more were shorter in the Norwegian study. This implies that Norwegian girls have similar or higher mean WHR in age 6-8 year and lower mean WHR in age after 9 years. Compared with Norwegian boys, mean WC and WHR was greater in Korean boys at all ages except for 7 and, 16-18 years. Data from a Greek study of 12- to 17-year-old adolescents ${ }^{27)}$ showed that mean WC is longer in both sexes aged 12-14 years than in Korean adolescents and similar or shorter in Greek adolescents aged 15-18 years. Mean WHR is higher in Greek boys aged under 14 years, similar in those aged 15, 16, 18 years, and shorter in those aged 17 years. The mean WHR of Greek girls is higher in 12 years old, similar in 13-14 years old, and shorter in 15-18 years old 
Table 2. Percentile values of waist circumference $(\mathrm{cm})$ by sex and age

\begin{tabular}{|c|c|c|c|c|c|c|c|c|c|c|}
\hline \multirow{2}{*}{ Sex } & \multirow{2}{*}{$\begin{array}{c}\text { Age } \\
\text { (yr) }\end{array}$} & \multicolumn{9}{|c|}{ Percentile } \\
\hline & & $3 r d$ & 5 th & 10th & 25th & 50th & 75th & 90th & 95th & 97th \\
\hline \multirow[t]{13}{*}{ Boys } & 6 & 45.8 & 46.7 & 47.8 & 50.0 & 53.2 & 56.8 & 62.5 & 66.5 & 68.6 \\
\hline & 7 & 47.9 & 48.1 & 49.5 & 51.7 & 54.8 & 59.2 & 65.6 & 69.0 & 70.2 \\
\hline & 8 & 48.8 & 49.4 & 51.0 & 53.5 & 57.7 & 64.0 & 71.8 & 76.0 & 78.2 \\
\hline & 9 & 50.1 & 51.2 & 52.5 & 55.3 & 59.4 & 66.8 & 74.2 & 79.4 & 83.4 \\
\hline & 10 & 51.8 & 52.9 & 54.1 & 57.5 & 63.9 & 72.3 & 77.8 & 82.0 & 83.9 \\
\hline & 11 & 52.4 & 54 & 56.3 & 59.8 & 65.7 & 73.1 & 81.4 & 86.0 & 89.1 \\
\hline & 12 & 54.8 & 55.4 & 58.0 & 61.0 & 66.8 & 74.7 & 82.3 & 86.6 & 90.2 \\
\hline & 13 & 56.5 & 57.9 & 59.7 & 62.9 & 68.5 & 77.0 & 85.0 & 88.8 & 90.6 \\
\hline & 14 & 58.5 & 59.5 & 61.5 & 64.7 & 69.8 & 79.1 & 88.0 & 92.8 & 96.2 \\
\hline & 15 & 60.0 & 61.2 & 63.2 & 66.8 & 71.7 & 80.2 & 88.1 & 94.6 & 96.9 \\
\hline & 16 & 61.7 & 62.3 & 64.0 & 67.8 & 72.4 & 79.4 & 87.8 & 92.9 & 98.0 \\
\hline & 17 & 61.1 & 62.4 & 63.8 & 68.0 & 73.5 & 80.3 & 87.2 & 93.6 & 99.9 \\
\hline & 18 & 61.8 & 63.5 & 65.2 & 69.8 & 75.5 & 82.3 & 89.5 & 96.9 & 99.8 \\
\hline \multirow[t]{13}{*}{ Girls } & 6 & 45.0 & 45.6 & 46.6 & 48.8 & 51.5 & 55.2 & 58.5 & 60.3 & 63.3 \\
\hline & 7 & 45.4 & 46.3 & 47.8 & 50.2 & 53.2 & 57.0 & 61.8 & 64.6 & 67.2 \\
\hline & 8 & 46.6 & 47.3 & 49.2 & 51.7 & 54.9 & 60.5 & 65.6 & 69.5 & 72.2 \\
\hline & 9 & 47.5 & 49.1 & 50.8 & 54.0 & 57.8 & 64.2 & 70.7 & 74.8 & 78.1 \\
\hline & 10 & 50.2 & 51.0 & 52.6 & 55.4 & 59.6 & 65.8 & 71.9 & 76.1 & 78.3 \\
\hline & 11 & 52.0 & 52.7 & 54.6 & 57.5 & 62.1 & 68.6 & 76.5 & 79.0 & 80.6 \\
\hline & 12 & 53.1 & 54.2 & 56.4 & 60.0 & 64.6 & 69.8 & 75.5 & 79.5 & 82.4 \\
\hline & 13 & 56.3 & 57.6 & 59.1 & 61.6 & 66.9 & 71.7 & 76.6 & 80.2 & 83.2 \\
\hline & 14 & 56.5 & 58.8 & 60.0 & 63.0 & 67.0 & 73.0 & 78.9 & 82.8 & 84.2 \\
\hline & 15 & 57.5 & 57.8 & 59.9 & 62.6 & 67.2 & 72.8 & 77.9 & 81.5 & 85.4 \\
\hline & 16 & 57.6 & 58.4 & 60.8 & 64.9 & 68.5 & 73.1 & 80.4 & 84.5 & 87.7 \\
\hline & 17 & 58.5 & 59.4 & 61.0 & 65.0 & 68.4 & 74.3 & 81.8 & 86.0 & 88.2 \\
\hline & 18 & 58.2 & 60.3 & 62.1 & 65.5 & 69.9 & 75.1 & 80.6 & 84.3 & 87.8 \\
\hline
\end{tabular}

than Korean girls. Mean WC and WHR were greater in Portuguese adolescents aged 15-18 years than in Korean adolescents. ${ }^{28)}$ Data from Thailand shows 6-12 years old girls have longer mean WC than Korean and Thai boys have similar or shorter WC except at 7 years old. Mean WHR of Thai adolescents were higher than Korean adolescents in all ages. ${ }^{29)}$ In the report for Hong Kong Chinese children aged 6-18 years, mean WC and WHR were much lower than values shown than Korean children. ${ }^{30)}$ Except for Portugal, in many countries, the WHR fluctuation does not appear to be largely significant after 13 years for men and after 11 years for women. The WHR pattern of the adolescent period seems to be similar, although there may be national and ethnic differences.

According to the results of this study, WC is lower overall than the reference data obtained from the 2007 Korean National Growth Charts, based on measurements form 1997 and 2005, when obesity in children and adolescents had already increased. The WC and WHR were not included on the 2017 Korean National Growth Chart which was established by using the data before the increase of obesity in consideration of the increase trend of obesity. ${ }^{31)}$ Therefore, considering the data showed that both mean WC and WHR have remained similar over 10 years, it may be necessary to make a new WC and WHR reference based on the 2017 Korean National Growth Charts.

The differences of WHR between boys and girls before 13 years of age exist through all 4 waves of KNHANES showing a peak at 10 years of age. Similar differences between sexes are seen in the WHR reference made using the previous 2007 growth chart. ${ }^{22)}$ These differences between sexes could be found in some other countries. In Hong Kong Chinese children, the differences between sexes were similar to those of Korean children, with a peak difference seen at 10-12 years of age. ${ }^{30)}$ Norwegian adolescents have similar differences to Korean children, and the peak difference is observed at 11 and 16 years of age. ${ }^{26)}$ WHR from Greek boys aged 12-17 years was higher than from girls. ${ }^{27)}$ In the study of Portuguese children and adolescents, 15-18 year old girls had higher WHR than boys. ${ }^{28)}$ WHR data from United Sates and Thailand did not show specific patterns or differences. ${ }^{29,32)}$

There are 2 opposing positions on the use of a universal cutoff of 
Kim MS, et al. • Waist circumference and waist-height ratio in Korean children

Table 3. Percentile values of waist-height ratio by sex and age

\begin{tabular}{|c|c|c|c|c|c|c|c|c|c|c|}
\hline \multirow{2}{*}{ Sex } & \multirow{2}{*}{$\begin{array}{l}\text { Age } \\
(y r)\end{array}$} & \multicolumn{9}{|c|}{ Percentile } \\
\hline & & $3 r d$ & 5th & 10th & 25th & 50th & 75th & 90th & 95th & 97th \\
\hline \multirow[t]{13}{*}{ Boys } & 6 & 0.389 & 0.393 & 0.403 & 0.418 & 0.444 & 0.473 & 0.516 & 0.540 & 0.560 \\
\hline & 7 & 0.382 & 0.389 & 0.397 & 0.415 & 0.436 & 0.466 & 0.51 & 0.532 & 0.555 \\
\hline & 8 & 0.378 & 0.383 & 0.394 & 0.412 & 0.437 & 0.480 & 0.529 & 0.556 & 0.586 \\
\hline & 9 & 0.375 & 0.381 & 0.391 & 0.407 & 0.435 & 0.480 & 0.528 & 0.563 & 0.582 \\
\hline & 10 & 0.368 & 0.380 & 0.391 & 0.409 & 0.444 & 0.499 & 0.544 & 0.559 & 0.572 \\
\hline & 11 & 0.361 & 0.368 & 0.382 & 0.401 & 0.440 & 0.494 & 0.529 & 0.555 & 0.587 \\
\hline & 12 & 0.361 & 0.368 & 0.374 & 0.393 & 0.423 & 0.475 & 0.523 & 0.547 & 0.565 \\
\hline & 13 & 0.349 & 0.359 & 0.364 & 0.387 & 0.417 & 0.468 & 0.513 & 0.539 & 0.564 \\
\hline & 14 & 0.352 & 0.357 & 0.368 & 0.387 & 0.413 & 0.463 & 0.524 & 0.550 & 0.563 \\
\hline & 15 & 0.353 & 0.360 & 0.374 & 0.389 & 0.417 & 0.464 & 0.509 & 0.534 & 0.558 \\
\hline & 16 & 0.349 & 0.360 & 0.370 & 0.390 & 0.420 & 0.461 & 0.505 & 0.542 & 0.565 \\
\hline & 17 & 0.347 & 0.363 & 0.374 & 0.391 & 0.420 & 0.465 & 0.508 & 0.542 & 0.564 \\
\hline & 18 & 0.359 & 0.365 & 0.376 & 0.398 & 0.433 & 0.471 & 0.518 & 0.544 & 0.577 \\
\hline \multirow[t]{13}{*}{ Girls } & 6 & 0.378 & 0.385 & 0.396 & 0.414 & 0.436 & 0.462 & 0.484 & 0.506 & 0.515 \\
\hline & 7 & 0.372 & 0.379 & 0.386 & 0.404 & 0.424 & 0.452 & 0.486 & 0.506 & 0.516 \\
\hline & 8 & 0.360 & 0.373 & 0.380 & 0.400 & 0.425 & 0.461 & 0.499 & 0.526 & 0.533 \\
\hline & 9 & 0.359 & 0.366 & 0.381 & 0.398 & 0.426 & 0.469 & 0.511 & 0.531 & 0.550 \\
\hline & 10 & 0.360 & 0.365 & 0.375 & 0.391 & 0.416 & 0.453 & 0.490 & 0.515 & 0.537 \\
\hline & 11 & 0.349 & 0.356 & 0.371 & 0.390 & 0.412 & 0.458 & 0.500 & 0.522 & 0.530 \\
\hline & 12 & 0.353 & 0.358 & 0.367 & 0.389 & 0.417 & 0.447 & 0.480 & 0.500 & 0.525 \\
\hline & 13 & 0.357 & 0.364 & 0.375 & 0.393 & 0.424 & 0.454 & 0.486 & 0.506 & 0.516 \\
\hline & 14 & 0.358 & 0.368 & 0.375 & 0.395 & 0.418 & 0.453 & 0.493 & 0.512 & 0.534 \\
\hline & 15 & 0.356 & 0.361 & 0.373 & 0.392 & 0.419 & 0.448 & 0.489 & 0.518 & 0.531 \\
\hline & 16 & 0.355 & 0.368 & 0.382 & 0.402 & 0.426 & 0.458 & 0.496 & 0.528 & 0.542 \\
\hline & 17 & 0.361 & 0.370 & 0.378 & 0.400 & 0.427 & 0.459 & 0.502 & 0.534 & 0.545 \\
\hline & 18 & 0.363 & 0.376 & 0.386 & 0.407 & 0.434 & 0.462 & 0.505 & 0.536 & 0.549 \\
\hline
\end{tabular}

Table 4. Comparison between different cutoff values of waist-height ratio to detect cardiometabolic risk factors

\begin{tabular}{|c|c|c|c|c|c|c|}
\hline Parameter & $\begin{array}{c}\text { Area under the curve } \\
\text { (95\% confidence interval) }\end{array}$ & Cutoff* & Sensitivity & Specificity & Positive predictive value & Negative predictive value \\
\hline \multirow[t]{2}{*}{ Abdominal obesity } & 0.985 (0.985-0.985) & 0.480 & 97.6 & 91.3 & 54.7 & 99.7 \\
\hline & & 0.500 & 84.9 & 96.7 & 73.5 & 98.3 \\
\hline \multirow[t]{2}{*}{ Hyperglycemia } & $0.596(0.594-0.598)$ & 0.442 & 53.1 & 65.7 & 8.4 & 95.9 \\
\hline & & 0.500 & 19.4 & 89.7 & 10.0 & 94.9 \\
\hline \multirow[t]{2}{*}{ Elevated HbA1c } & $0.545(0.543-0.546)$ & 0.440 & 44.2 & 65.3 & 24.3 & 82.3 \\
\hline & & 0.500 & 16.2 & 89.6 & 28.1 & 80.9 \\
\hline \multirow[t]{2}{*}{ High triglyceride } & $0.735(0.733-0.736)$ & 0.462 & 59.0 & 78.4 & 19.4 & 95.5 \\
\hline & & 0.500 & 34.3 & 91.0 & 25.3 & 94.0 \\
\hline \multirow[t]{2}{*}{ Low HDL cholesterol } & $0.645(0.644-0.646)$ & 0.438 & 56.2 & 67.1 & 32.9 & 84.2 \\
\hline & & 0.500 & 21.1 & 92.2 & 43.7 & 80.2 \\
\hline \multirow[t]{2}{*}{ Elevated blood pressure } & $0.609(0.608-0.610)$ & 0.462 & 39.3 & 78.9 & 30.3 & 84.8 \\
\hline & & 0.500 & 20.9 & 91.3 & 35.9 & 83.1 \\
\hline
\end{tabular}

${ }^{*}$ Cutoff values were calculated as to point where the sum of sensitivity and specificity was maximized using receiver operating characteristic curve analysis.

Cardiometabolic risk factors were defined as follows: abdominal obesity, waist circumference $\geq 90$ th percentile for age and sex; hyperglycemia, fasting plasma glucose $\geq 100 \mathrm{mg} / \mathrm{dL}$; elevated glycated hemoglobin ( $\mathrm{HbA}_{1 \mathrm{c}}$ ), $\mathrm{HbA}_{1 \mathrm{c}} \geq 5.7 \%$; high triglyceride, triglyceride $\geq 150 \mathrm{mg} / \mathrm{dL}$; low high-density lipoprotein (HDL) cholesterol, $\mathrm{HDL}<40 \mathrm{mg} / \mathrm{dL}$ for boys aged 10-18 years, $<40 \mathrm{mg} / \mathrm{dL}$ for girls aged 10-16 years and $<50 \mathrm{mg} / \mathrm{dL}$ for girls aged $\geq 16$ years; and elevated blood pressure, Systolic or diastolic blood pressuer $\geq 90$ th percentile for age and sex. 

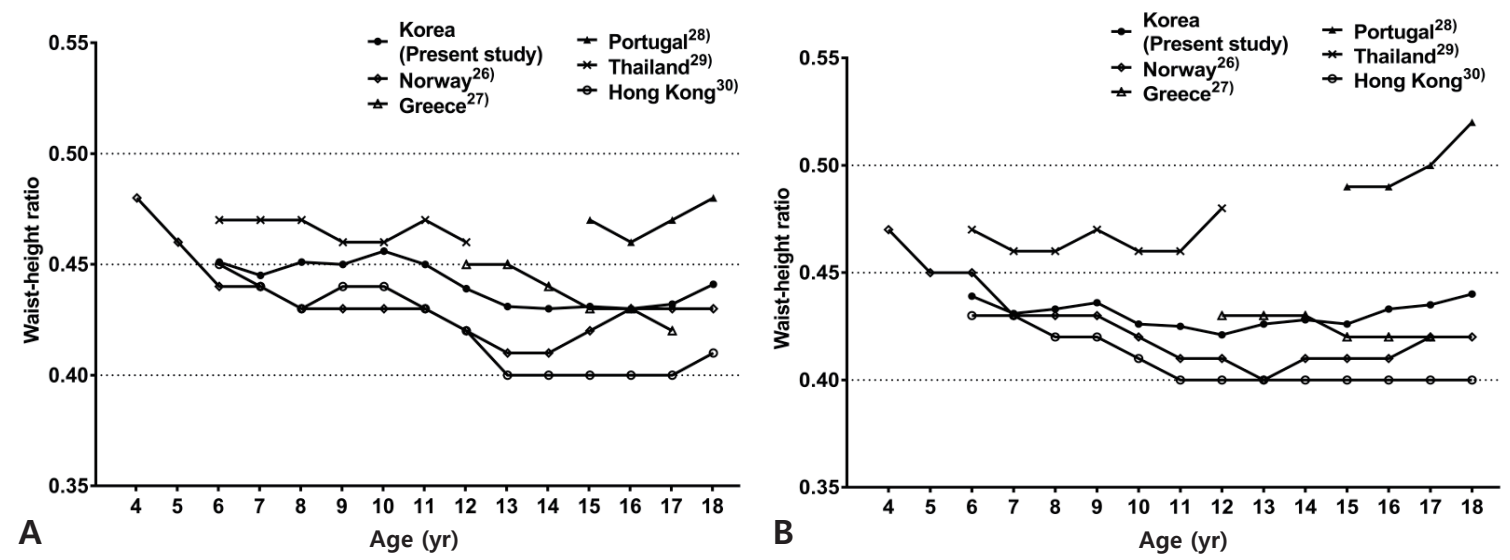

Fig. 2. Age- and sex-specific mean waist-to-height ratios of children and adolescents from different countries. Boys (A) and girls (B).

0.5 for WHR. In a study by McCarthy and Ashwell, a WHR of 0.5 was proposed ('Keep your WC to less than half your height') as a unique cut-off to predict cardiovascular risk in individual of all ages including children. ${ }^{33)}$ Whereas, Inokuchi et al. ${ }^{34)}$ recommend age and sex specific reference values and preclude using a universal cutoff of 0.5. In previous studies in Korea, Gil et al. ${ }^{22}$ suggested that the optimal WHR for determination of obesity was 0.51 in 6-18 year old boys and 0.48 in girls of the same age. In the study by Choi et al., ${ }^{19)}$ the optimal WHR cutoff for metabolic syndrome was 0.44 in 10- to 19 -year-old boys and 0.43 in girls, which is less than the value of 0.5. These cutoffs are generated taking into account the ethnic and sex-specific features in order to improve accuracy. These studies are partially in line with Ashwell's proposal to use a universal cutoff. We have also made efforts to find an appropriate cutoff based on the KNHANES data. In this study, the optimal WHR cutoff for abdominal obesity was 0.48 in Korean children and adolescents aged 1318 years. The other cutoff values for cardiometabolic risk were not useful for practical clinical applications. All cutoff values obtained were lower than 0.5. Comparing with the cutoff value of 0.48 for abdominal obesity, 0.5 as candidate of universal value showed higher specificity in order to reduce false negative results. This data suggests that if WHR of a subject was 0.5 or higher, it would be more likely that the individual has abdominal obesity. However, it is necessary to detect obesity early and managed it efficiently. This is of particular importance, as abdominal obesity is strongly associated with many metabolic abnormalities, therefore, active interventions are required even at a lower WHR cutoff than 0.5.

There are several limitations on this study. First, this was a crosssectional study. Thus, it cannot provide enough evidence of predictive values of WHR for cardiometabolic risk. To compensate for these shortcomings, 4 KNHANES waves over a decade were collected and presented, but due to existing time intervals between waves, these data cannot fully explain the trends seen in children and adolescents during 2005-2015. Future prospective cohort studies are needed for more rigorous evaluations. Second, because the feature of differences between sexes on distribution of WHR, we only could not generate a reference for children between 6 to 18 years old. Additionally, to create optimal WC cutoff values for cardiometabolic risk, different reference values must be applied, depending on sex and age. Therefore, the numbers of subjects for each sex and age should be sufficient, but, present study did not provide enough numbers, and analysis was not conducted. Thus, larger-scale cohort studies should be performed. Finally, onset of puberty that could be associated with obesity and other cardiometabolic disease was not reflected in this study.

In conclusion, WC and WHR in Korean children and adolescents have shown no secular change over the past 10 years. The mean WC values of both sexes from the present study were lower than those from the 2007 Korean National Growth Charts. WHR was higher in boys than in girls but, there is no difference in adolescents over 13 years old. Considering the distribution of WHR by age and sex, the value of 0.48 as an optimal cutoff could be applied for Korean adolescents over 13 years old and be helpful to diagnose abdominal obesity. With regard to the lack of secular change in WC, it might be necessary to make a new WC and WHR reference based on 2017 Korean National Growth Charts.

\section{Conflicts of interest}

No potential conflict of interest relevant to this article was reported.

\section{Supplementary material}

Supplementary Tables 1-3 can be found via https://doi.org/ 10.3345/kjp.2018.07038. 


\section{References}

1. Swinburn BA, Sacks G, Hall KD, McPherson K, Finegood DT, Moodie ML, et al. The global obesity pandemic: shaped by global drivers and local environments. Lancet 2011;378:804-14.

2. Wang Y, Lobstein T. Worldwide trends in childhood overweight and obesity. Int J Pediatr Obes 2006;1:11-25.

3. Weiss R, Caprio S. The metabolic consequences of childhood obesity. Best Pract Res Clin Endocrinol Metab 2005;19:405-19.

4. Weiss R, Dziura J, Burgert TS, Tamborlane WV, Taksali SE, Yeckel $\mathrm{CW}$, et al. Obesity and the metabolic syndrome in children and adolescents. N Engl J Med 2004;350:2362-74.

5. Franks PW, Hanson RL, Knowler WC, Sievers ML, Bennett PH, Looker HC. Childhood obesity, other cardiovascular risk factors, and premature death. N Engl J Med 2010;362:485-93.

6. Kahn HS, Valdez R. Metabolic risks identified by the combination of enlarged waist and elevated triacylglycerol concentration. Am J Clin Nutr 2003;78:928-34.

7. Katzmarzyk PT, Srinivasan SR, Chen W, Malina RM, Bouchard C, Berenson GS. Body mass index, waist circumference, and clustering of cardiovascular disease risk factors in a biracial sample of children and adolescents. Pediatrics 2004;114:e198-205.

8. Gower BA, Nagy TR, Goran MI. Visceral fat, insulin sensitivity, and lipids in prepubertal children. Diabetes 1999;48:1515-21.

9. August GP, Caprio S, Fennoy I, Freemark M, Kaufman FR, Lustig RH, et al. Prevention and treatment of pediatric obesity: an endocrine society clinical practice guideline based on expert opinion. J Clin Endocrinol Metab 2008;93:4576-99.

10. Yajnik CS, Yudkin JS. The Y-Y paradox. Lancet 2004;363:163.

11. Ashwell M, Gunn P, Gibson S. Waist-to-height ratio is a better screening tool than waist circumference and BMI for adult cardiometabolic risk factors: systematic review and meta-analysis. Obes Rev 2012; 13:275-86.

12. Browning LM, Hsieh SD, Ashwell M. A systematic review of waist-toheight ratio as a screening tool for the prediction of cardiovascular disease and diabetes: 0.5 could be a suitable global boundary value. Nutr Res Rev 2010;23:247-69.

13. Brambilla P, Bedogni G, Heo M, Pietrobelli A. Waist circumferenceto-height ratio predicts adiposity better than body mass index in children and adolescents. Int J Obes (Lond) 2013;37:943-6.

14. Kromeyer-Hauschild K, Neuhauser H, Schaffrath Rosario A, Schienkiewitz A. Abdominal obesity in German adolescents defined by waist-to-height ratio and its association to elevated blood pressure: the KiGGS study. Obes Facts 2013;6:165-75.

15. Freedman DS, Kahn HS, Mei Z, Grummer-Strawn LM, Dietz WH, Srinivasan SR, et al. Relation of body mass index and waist-to-height ratio to cardiovascular disease risk factors in children and adolescents: the Bogalusa Heart Study. Am J Clin Nutr 2007;86:33-40.

16. Bauer KW, Marcus MD, El ghormli L, Ogden CL, Foster GD. Cardiometabolic risk screening among adolescents: understanding the utility of body mass index, waist circumference and waist to height ratio. Pediatr Obes 2015;10:329-37.

17. Kuba VM, Leone C, Damiani D. Is waist-to-height ratio a useful indicator of cardio-metabolic risk in 6-10-year-old children? BMC Pediatr 2013;13:91.

18. Chung IH, Park S, Park MJ, Yoo EG. Waist-to-Height ratio as an index for cardiometabolic risk in adolescents: results from the 1998-2008 KNHANES. Yonsei Med J 2016;57:658-63.

19. Choi DH, Hur YI, Kang JH, Kim K, Cho YG, Hong SM, et al. Usefulness of the waist circumference-to-height ratio in screening for obesity and metabolic syndrome among Korean children and adolescents: Korea National Health and Nutrition Examination Survey, 20102014. Nutrients 2017;9. pii: E256. doi: 10.3390/nu9030256

20. Lee KK, Park HS, Yum KS. Cut-off values of visceral fat area and waist-to-height ratio: diagnostic criteria for obesity-related disorders in Korean children and adolescents. Yonsei Med J 2012;53:99-105.

21. Cho WK, Kim H, Lee HY, Han KD, Jeon YJ, Jung IA, et al. Insulin resistance of normal weight central obese adolescents in Korea stratified by waist to height ratio: results from the Korea National Health and Nutrition Examination Surveys 2008-2010. Int J Endocrinol 2015;2015:158758.

22. Gil JH, Lee MN, Lee HA, Park H, Seo JW. Usefulness of the waist circumference-to-height ratio in screening for obesity in Korean children and adolescents. Korean J Pediatr Gastroenterol Nutr 2010; 13:180-92.

23. Moon JS, Lee SY, Nam CM, Choi JM, Choe BK, Seo JW, et al. 2007 Korean National Growth Charts: review of developmental process and an outlook. Korean J Pediatr 2008;51:1-25.

24. Lee CG, Moon JS, Choi JM, Nam CM, Lee SY, Oh K, et al. Normative blood pressure references for Korean children and adolescents. Korean J Pediatr 2008;51:33-41.

25. Park MJ, Boston BA, Oh M, Jee SH. Prevalence and trends of metabolic syndrome among Korean adolescents: from the Korean NHANES survey, 1998-2005. J Pediatr 2009;155:529-34.

26. Brannsether B, Roelants M, Bjerknes R, Júliusson PB. Waist circumference and waist-to-height ratio in Norwegian children 4-18 years of age: reference values and cut-off levels. Acta Paediatr 2011;100: 1576-82.

27. Bacopoulou F, Efthymiou V, Landis G, Rentoumis A, Chrousos GP. Waist circumference, waist-to-hip ratio and waist-to-height ratio reference percentiles for abdominal obesity among Greek adolescents. BMC Pediatr 2015;15:50.

28. Santos R, Moreira C, Ruiz JR, Vale S, Soares-Miranda L, Moreira P, et al. Reference curves for BMI, waist circumference and waist-to-height ratio for Azorean adolescents (Portugal). Public Health Nutr 2012; 15:13-9.

29. Rerksuppaphol S, Rerksuppaphol L. Waist circumference, waist-toheight ratio and body mass index of Thai children: secular changes and updated reference standards. J Clin Diagn Res 2014;8:PC05-9.

30. Sung RY, So HK, Choi KC, Nelson EA, Li AM, Yin JA, et al. Waist circumference and waist-to-height ratio of Hong Kong Chinese children. BMC Public Health 2008;8:324.

31. Kim JH, Yun S, Hwang SS, Shim JO, Chae HW, Lee YJ, et al. The 2017 Korean National Growth Charts for children and adolescents: development, improvement, and prospects. Korean J Pediatr 2018;61: 135-49.

32. Sharma AK, Metzger DL, Daymont C, Hadjiyannakis S, Rodd CJ. LMS tables for waist-circumference and waist-height ratio Z-scores in children aged 5-19 y in NHANES III: association with cardio-metabolic risks. Pediatr Res 2015;78:723-9.

33. McCarthy HD, Ashwell M. A study of central fatness using waist-toheight ratios in UK children and adolescents over two decades supports the simple message--'keep your waist circumference to less than half your height'. Int J Obes (Lond) 2006;30:988-92.

34. Inokuchi M, Matsuo N, Takayama JI, Hasegawa T. Waist-to-height ratio centiles by age and sex for Japanese children based on the 19781981 cross-sectional national survey data. Int J Obes (Lond) 2016; 40:65-70. 